
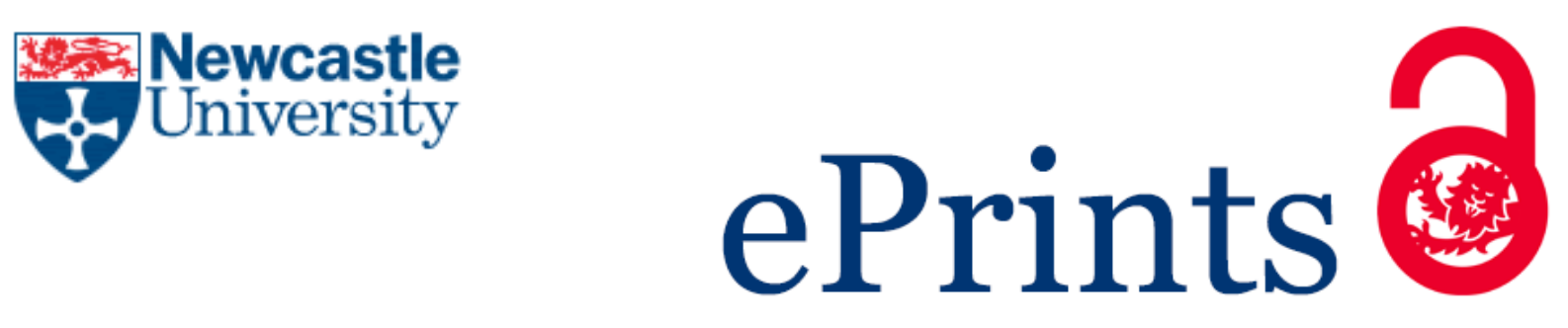

Duxbury D. Behavioral finance: insights from experiments II: biases, moods and emotions. Review of Behavioral Finance 2015, 7(2), 151-175.

Copyright:

(c) Emerald, 2015.

DOI link to article:

http://dx.doi.org/10.1108/RBF-09-2015-0037

Date deposited:

$11 / 11 / 2015$

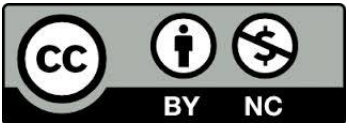

This work is licensed under a Creative Commons Attribution-NonCommercial 3.0 Unported License 
Published paper, please cite as:

Duxbury, D. (2015). Behavioral Finance: Insights from experiments II: Biases, moods and emotions. Review of Behavioral Finance, 7(2), 151 - 175.

DOI: $\underline{10.1108 / R B F-09-2015-0037}$

\title{
Behavioral Finance: Insights from experiments II: Biases, moods and emotions
}

\author{
Darren Duxbury ${ }^{a}$ \\ a Newcastle University Business School, \\ Newcastle University, Newcastle-upon-Tyne, NE1 4SE, UK
}

\begin{abstract}
Purpose

The aim in this second of two companion papers is to further review the insights provided by experimental studies examining financial decisions and market behavior.

\section{Design/methodology/approach}

Focus is directed on those studies examining explicitly, or with direct implications for, the most robustly identified phenomena or stylized facts observed in behavioral finance. The themes for this second paper are biases, moods and emotions.
\end{abstract}

\section{Findings}

Experiments complement the findings from empirical studies in behavioral finance by avoiding some of the limitations or assumptions implicit in such studies.

\section{Originality/value}

We synthesize the valuable contribution made by experimental studies in extending our knowledge of how biases, moods and emotions influence the financial behavior of individuals, highlighting the role of experimental studies in policy design and intervention.

Keywords: Experimental finance, Experimental economics, Under/ overreaction, Overconfidence, Disposition effect, House money effect, Escalation of commitment, Moods, Emotions 


\section{Introduction}

Following on from the companion paper, Duxbury (2015), in which we review the evidence from experiments testing specific aspects of finance theory and market anomalies, along with other stylized facts, in this paper we examine the contribution of experimental studies to our understanding of heuristics and biases at the heart of behavioral models in finance (e.g. under/overreaction, overconfidence) and observed investor behavior (e.g. the impact of prior outcomes), along with the influence of moods and emotions on financial behavior. We expand on the range of issues identified by Muradoglu and Harvey (2012) in the special issue of this journal on "Psychological factors in financial decisions". Beginning in the next section with under/overreaction, we focus on those experiments motivated by behavioral models of investor reaction to information, before turning to discuss the experimental evidence in relation to overconfidence in the following section. In section 4, we evaluate the impact of prior outcomes on financial behavior, including experimental studies examining the disposition and house money effects, before turning in section 5 to review the experimental evidence in relation to investor mood and emotion. Section 6 concludes, drawing on the evidence presented in both companion papers, with a discussion of the strengths and insights to be gained from experimental studies designed either to provide direct tests of behavioral models or of investor behavior in settings where key variables of interest can be controlled, manipulated or observed direct, and hence free of the need for proxies.

\section{Under/overreaction}

Momentum or contrarian trading strategies have been shown to produce abnormal profits over varying time horizons and in a range of markets (e.g. DeBondt and Thaler, 1985; Jegadeesh and Titman, 1993; Rouwenhorst, 1998). A number of behavioral models seek to understand the existence of such profits by examining the under/overreaction of investors to information (e.g. Barberis et al., 1998; Daniel et al. 1998; Hong and Stein, 1999; see Hirshleifer, 2001, for a 
review). Investor under/overreaction is an area that has witnessed a considerable amount of experimental examination. We focus here on those experiments motivated by the above theoretical models, regrettably excluding a number of interesting studies.

While Fama (1998) claims under/overreaction cancel out, leaving markets efficient, Bloomfield et al. (2000) note this is true only if under/overreactions are unsystematic, hence they investigate experimentally whether information reliability leads to under/overreaction in systematic ways. Examining this issue empirically using field data is difficult, because of problems measuring reliability of information. Their results show that prices and value estimates underreact more as the reliability of information increases. Underreaction to new information can manifest in momentum or drift over time (e.g. post-earnings announcement drift). The results in Bloomfield et al. (2000) show, therefore, that drift is associated with more reliable information in a systematic and predictable way, thus challenging Fama's (1998) view.

In two experiments, Bloomfield and Hales (2002) test the model of Barberis et al. (1998) directly by investigating whether under/overreaction to changes in a random walk are influenced by the prevalence of recent reversals. Half the participants were informed that the sequence was derived from a random process, while the other half were told the process derived from "surprises" in firm performance. Bloomfield and Hales (2002) measure investors' beliefs via a task in which participants maximize their expected earnings by setting prices equal to their estimated probability of an upward change (i.e. a price of 50). Bloomfield and Hales (2002) test for the directional relationship of deviations with the rate of past reversals, hence they investigate whether predictions deviate in a manner consistent with regime-shifting. Their results are consistent with the regime-shifting model of Barberis et al. (1998), with investors under/overreacting less/more to changes preceded by fewer reversals. Debriefing questions reveal the majority of participants, whether they were informed the sequences were derived from the toss of a coin or earnings surprises, use past patterns to predict future changes. 
In an experimental setting that closely resembles the model of Hong and Stein (1999), Bloomfield et al. (2009) assess the robustness of momentum and reversal effects, investigating the role of informed and uninformed traders in these phenomena. In Experiment 1, human uninformed traders (who must trade based on past price changes) interact with robot informed traders programmed to behave like "newswatchers" in the model. The results show that uninformed traders engage in momentum trading, which results in overreaction to news promoting further short-term price momentum and subsequent long-term reversal as the market corrects. In Experiment 2, news is disseminated to different human informed traders at different times, as per the "newswatchers" in the model. Following the predictions of the model, informed traders are unable to infer the information of other traders by observing market activity and this leads to short-term price momentum, though little evidence of long-term reversal is observed. Experiment 3 introduces human uninformed traders (who must trade based on past price changes) into markets with human informed traders that play the role of "newswatchers" in the model. The findings show that uninformed traders do not propel short term momentum, but do drive long-term reversal. Bloomfield et al. (2009) observe, however, that while the results are consistent with the model, the underlying cause is not, with uninformed participants trading like contrarian not momentum investors as assumed in the model.

Lin and Rassenti (2012) also devise an experiment closely aligned to the model of Hong and Stein (1999), in which information is dispersed over time and asymmetrically between investors to generate a process of information diffusion akin to that in Hong and Stein (1999). Similar to Bloomfield et al. (2009), Lin and Rassenti (2012) implement a fundamental value that varies with a random walk, though they do so across three different settings: a bullish/bearish/neutral environment where the asset value is expected to rise/fall/remain constant. A novel feature is the exclusion of information asymmetry in a public information treatment, allowing an examination of whether anomalies disappear if information is public. 
Consistent with Hong and Stein (1999) and Bloomfield et al. (2009), results in Lin and Rassenti (2012) confirm that asymmetric information contributes to price under-reaction, however, a majority of under-reaction is observed under perfectly symmetric public information. Thus, the limited information aggregation argument of Hong and Stein (1999) does not account fully for under-reaction. The experimental design in Lin and Rassenti (2012) allows comparative tests of the explanatory power of the models of under/overreaction by Barberis et al. (1998), Daniel et al. (1998) and Hong and Stein (1999) based on their differential predictions. The evidence of insufficient adjustments to surprises and observed inertia supports the model of Barberis et al. (1998) in which conservatism leads investors to update their beliefs slowly in response to new information. The other models fail to fit the experimental data.

A strength of the experimental approach is the ability to identify, and manipulate, the fundamental value of the traded asset. The importance of this is well demonstrated by Lin and Rassenti (2012). In an examination of conventional return autocorrelations they observe, after taking account of fundamentals, that the traditional approach of examining continuation/reversal of return signs fails to consistently indicate true under and over-reaction.

In a novel experimental study, Asparouhova et al (2009) note that the model of Barberis et al. (1998) implies that the probability of a streak continuing increases monotonically with streak length. They contrast this with the implications of the model in Rabin (2002), based on the law of small numbers, in which streak length and expectation of continuation is nonmonotonic; overestimation of the probability of a short streak reversing and of a long streak continuing. Asparouhova et al. (2009) exploit the differences in implications to conduct comparative tests of the explanatory power of the two models. In their experiment, participants observe randomly generated sequences of binary outcomes (up/down) and are asked to provide an assessment of the likelihood that the next outcome will be "up". An incentive-compatible mechanism is employed to elicit participants' truthful revelation of their subjective probabilities. Asparouhova et al. (2009) use the experimental data to estimate the parameters of the two models and then 
test relative goodness of fit. While both models provide a better fit than benchmark models, the Rabin (2002) model provides a significantly better fit than the Barberis et al. (1998) model. Furthermore, regression analysis examining responses to streaks yields results consistent with the Rabin's (2002) model only.

A further novel test of the model of Barberis et al. (1998) is reported by Rotheli (2011) in an experimental study of how participants extrapolate simple patterns in financial time series. Rotheli (2011) contrasts the sophisticated Bayesian updating of probabilities in the regimeshifting model of Barberis et al. (1998) with a simple visual pattern-based extrapolation model. The predictions of the Barberis et al. (1998) model are at odds with the data and expectations elicited in the experiment cannot be explained by the Bayesian probability updating at the heart of their model.

\section{Overconfidence}

There has been much interest in the consequences of traders' overconfidence on financial decision making and the functioning of financial markets, with the development of a number of theoretical models of overconfidence in financial markets that make predictions about trader behavior and how this translates into market behavior (e.g. Daniel et al., 1998; Gervais and Odean, 2001; Odean, 1998b). In these models overconfidence is usually captured as an overestimation of the precision of one's information (i.e. miscalibration), with overconfident investors underestimating the variance of the error contained in their private signal. The models generally predict: increased overconfidence is associated with; i) increased trading volume, ii) increased price volatility, iii) excessive risk taking and lower expected utility.

Overconfidence in the behavioral finance literature has been examined empirically at both the individual-level and the market-level. Seminal studies examining overconfidence using individual-level data include Barber and Odean $(2000,2001)$ and Odean (1998b) who conclude that individual investors appear overconfident about their perceived information and trade too 
much to the detriment of their wealth. Using gender as a "natural" proxy for overconfidence (with men typically more overconfident than women), Barber and Odean (2001) find that men trade $45 \%$ more than women and that this is detrimental to their wealth (due to costs associated with high volume), with average return a full percentage point lower than for women and differences are most pronounced between single men and single women. Overconfidence has also been empirically linked to under-diversification (Goetzman and Kumar, 2008) and home bias (Kilka and Weber, 2000). Market-level studies of overconfidence (e.g. Statman et al., 2006; Kim and Nofsinger, 2003), typically examine the relationship between stock returns and trading volume, on the premise that high past returns (bull markets) proxy for overconfidence, and conclude that overconfidence is associated with higher trading volume. Chuang and Lee (2006) find that high stock returns Granger-cause high trading volume and that investors trade more aggressively in a bull market than in a bear market.

There are two directions that can be taken when testing the validity of theoretical models of overconfidence: i) test the model assumptions, and ii) test the model predictions. Empirical studies in behavioral finance adopt the second approach, whereby predictions of the link between market outcomes and investor overconfidence are tested by correlation of proxies (e.g. gender, high returns) or measures of overconfidence (bias score) and economic variables (e.g. trading volume). Hence empirical studies rely on using proxies of overconfidence and as such are subject to the shortcoming that overconfidence is never directly observed nor causal inference drawn. These problems can be overcome by the use of experimental methods that allow more confident inference about cause and effect relations to be drawn and which adopt the first approach.

Before reviewing the experimental evidence, it is important to identify inconsistencies and methodological issues in the psychology literature on overconfidence. Moore and Healy (2008) identify three distinct ways in which overconfidence has been defined in the psychology literature: The first definition relates to overestimation of ability, performance, chance of 
success, etc., which they label overestimation. The second definition arises when people believe themselves to be better than others, which they label overplacement, and which is commonly referred to as a "better than average" effect (or referential by Acker and Duck, 2008). The third relates to excessive certainty regarding the accuracy of one's beliefs, which they label overprecision, and which is commonly referred to as miscalibration.

The number of experimental studies of overconfidence in financial behavior is high and so there is a need to be selective; we largely focus on experiments based on a market setting. A number of closely related studies (Biais et al., 2005; Deaves et al., 2009; Glaser and Weber, 2007; Kirchler and Maciejovsky, 2002; Nelson et al., 2001) were published in relatively close temporal proximity. A range of findings emerge from these studies relating to miscalibration, trade volume, wealth effects and gender differences. Nelson et al. (2001) assess the effects of information strength (i.e. extremity) and weight (i.e. statistical reliability) on both individual and market-level miscalibration, along with investor trading behavior and wealth via dependent variables measuring individual value estimate, market price, number of shares traded and trading profit, respectively. Based on a coin-flipping task, Nelson et al. (2001) vary information strength (sample proportion; difference between the number of heads/tails in the sample) and weight (sample size; number of coin flips is high or low) simultaneously, to investigate how the two interact to impact calibration (overconfidence). They find that information with high strength and low weight promotes more extreme estimates of value (overconfidence) than the converse situation. Individuals with more extreme estimates, however, trade just as aggressively as individuals with less extreme estimates. As a result, the effects of information strength and weight on overconfidence (miscalibration) are comparable at the individual and market-level. Hence, they conclude that trading decisions neither exacerbate nor mitigate individual bias. Nelson et al. (2001) find that investors with high strength and low weight (overconfidence) lose wealth to relatively less-overconfident traders. This result is supported, by Biais et al. (2005) who 
find that overconfidence (miscalibration) reduces trading performance in their experimental asset market.

A number of surprising results emerge from this group of studies. First, contrary to predictions of overconfidence models employed in finance, both Biais et al. (2005) and Glaser and Weber (2007) fail to find a relationship between overconfidence (miscalibration) and trading volume. While overconfidence models almost exclusively adopt miscalibraton as their overconfidence measure of choice, in considering this finding Glaser and Weber (2007) note that the link between miscalibration and trading volume has not been established empirically or experimentally previously. Second, both Glaser and Weber (2007) and Deaves et al (2009) find that gender is unrelated to trading volume measures, contradicting the evidence of Barber and Odean (2001) who report that men trade more than women. Biais et al. (2005) do find evidence that men trade more than women, but while Barber and Odean (2001) use gender as a proxy for overconfidence, Biais et al. (2005) find no correlation between gender and miscalibration (overconfidence). Third, Kirchler and Maciejovsky (2002) examine two forms of overconfidence, miscalibration and the difference between objective accuracy and subjective certainty. While they find some evidence that overconfident traders (based on subjective confidence intervals) earn less than other traders in their experimental markets, they find no evidence to suggest that trading volume is negatively correlated with individual earnings. Kirchler and Maciejovsky (2002) conclude that individuals are not consistently overconfident, with evidence of both under- and overconfidence, though they also find inconsistencies across the two measures of overconfidence. Glaser and Weber (2007) and Deaves et al. (2009) find similar inconsistent results across different measures of overconfidence.

There is further evidence of dissimilarities across measures of overconfidence. For example, Acker and Duck (2008) distinguish different types of overconfidence, referring to miscalibration as stand-alone overconfidence and the better-than-average effect as 'referential' overconfidence, and examine the degree of correlation between the two. The extent of correlation between 
overconfidence measures is an important issue, particularly in the finance literature where it is common to define overconfidence in terms of a trader's mistaken belief in the precision of information (e.g. Daniel et al., 1998). While on first consideration this seems to relate directly to miscalibration, implicit is the assumption that precision is judged relative to the precision of other traders' information, which requires a referential judgement. Acker and Duck (2008) conduct an Internet-based stock-market game to examine the extent to which traders exhibit stand-alone and referential overconfidence, and the correlation between them. They also note that self-attribution bias plays an important supporting role in some models of overconfidence in the finance literature (e.g. Gervais and Odean, 2001; Daniel et al., 1998; Odean, 1998b), hence they investigate the co-existence of self-attribution bias and overconfidence, and the extent to which they are related. They provide evidence to confirm that both forms of overconfidence and self-attribution bias are present in their data, but that the two types of overconfidence do not appear to be related.

Using a survey field study of experts, along with questions that directly relate to their area of expertise, Kaustia and Perttula (2012) measure overconfidence amongst finance professionals and test for the impact of different debiasing methods. Results suggest that finance professionals are overconfident in terms of probability calibration, better-than-average beliefs, and unfounded confidence. Debiasing attempts had mixed success, with explicit written warnings found to reduce better-than-average overconfidence, while there was only limited success in reducing miscalibration based overconfidence. As a result, Kaustia and Perttula (2012) conclude that different types of overconfidence are distinct and respond differentially to debiasing techniques.

Based on a review of existing evidence and also new evidence they present themselves, Moore and Healy (2008) demonstrate that overestimation, overplacement, and overprecision are not different manifestations of the same underlying construct. Collectively, there is strong evidence in support of Moore and Healy's (2008) conclusion that the different types of 
overconfidence commonly examined, and sometimes confounded, in the literature are conceptually and empirically distinct constructs. The above finding of inconsistent results across measures of overconfidence is problematic, particularly from the perspective of the finance literature. Many studies assume, either explicitly or implicitly, that the different types of overconfidence are the same and this is true of the key behavioral models in the finance literature (e.g. Barber and Odean, 2001; Daniel et al., 1998; Odean, 1998b). Future theoretical models of overconfidence would benefit from greater clarity and precision in regard to the definitions and measures of overconfidence they employ.

A number of studies examine situations in which overconfidence can reverse to become underconfidence. Hoelzl and Rustichini (2005), for example, conduct an experiment where participants are required to choose among options and where task complexity is manipulated to be high or low. They find that choice behavior changes from overconfidence to underconfidence as the task changes from easy and familiar to difficult and non-familiar. The change in confidence is significant when monetary payments are at stake, but weak otherwise. In a very different experimental setting involving an investment task, Dittrich et al. (2005) also examine conditions under which overconfidence switches to underconfidence. They induce risk aversion and then examine actual investment choices for four different risky assets. Participants first select their own investment levels and are then presented with three alternative investment choices, one of which represents the optimal choice, and asked for their willingness to pay (WTP) and for their willingness to accept (WTA) to substitute their own-choice investment decision for one of the alternative investments. They define overconfidence as the persistent overevaluation of the own-choice investment decision. They show that overconfidence decreases as the participants own WTA/WTP increases, thus implying that they become less overconfident as their own perception of uncertainty (captured by WTA/WTP) increases. Hence, consistent with the findings in Hoelzl and Rustichini (2005), Dittrich et al. (2005) report decreased levels of overconfidence as task uncertainty increases. 
Fellner et al. (2004) examine egocentric biases (e.g. overconfidence) in simple portfolio choices. The task facing participants was to design individual portfolios, such that each combination of assets produced the same expected return and variance of returns. Participants were then presented with a choice between keeping their original, self-designed portfolio and switching to one of two alternative portfolios (the average portfolio and the portfolio designed by a self-selected expert). Reluctance to give up the individually selected portfolio in favour of an equally good alternative one, provides a measure of 'illusion of expertise' (overconfidence). Fellner et al. (2004) find that about two-thirds of the participants were prone to this behavioral tendency.

It is important to note, however, that implicit in their measure of 'illusion of expertise' (overconfidence) is the assumption that individuals are variance averse. This derives from the requirement that participants that design individual portfolios with equal expected return and variance of returns. Fellner et al. (2004) assume that participants should be indifferent between any combination of assets, irrespective of whether the portfolio was picked by themselves or by others. If participants are not variance averse, but instead are loss averse in the sense that they wish to avoid portfolios with high probabilities of loss (Duxbury and Summers, 2004), then they may still have a preference for a particular portfolio if they differ on probability of loss. Furthermore, it is conceivable, that the data may be explained by a desire to avoid regret, which has been shown to be greater for acts of commission than omission (e.g. Kahneman and Tversky 1982), rather than an overconfidence based explanation. We return to a discussion of the influence of emotions, along with moods, on financial decisions in section 5.

\section{The impact of prior outcomes}

At the heart of rational economic models of utility maximization is the assumption that individuals derive utility from final state wealth and are indifferent as to how they arrive at this terminal wealth. Hence, changes in wealth do not factor in the determination of utility, thus 
prior outcomes should be irrelevant to future decisions. In contrast, prospect theory is premised on the notion that individuals derive value from gains and losses relative to a reference point, with its S-shape value function depicting risk aversion/seeking in the gain/loss domain. A substantial body of evidence, from a variety of domains ranging from gambling and game shows to managerial and investment decisions, suggest that prior outcomes impact on individuals' decisions, but the evidence is mixed with behavior either consistent with prospect theory or the house money effect (Thaler and Johnson, 1990), namely the tendency for risk taking following prior gains and more risk aversion following prior losses.

In the finance literature there is ample evidence that prior outcomes impact investors' decisions. The disposition effect (Shefrin and Statman, 1985) refers to the tendency of investors to sell winners too soon (risk aversion after gains), but hold losers too long (risk seeking after losses), consistent with prospect theory. Odean (1998a) finds that individual investors show a strong propensity for realizing winners rather than losers in their portfolios. The disposition effect is observed in a variety of financial markets and across a range of trader types; including Finnish Central Securities Depository trades (Grinblatt and Keloharju (2001), day trader transactions (Jordan and Diltz, 2004), professionally managed accounts at an Israeli brokerage house (Shapira and Venezia, 2001), Chinese stock market investors (Feng and Seasholes, 2005; Chen et al. 2007). The house money effect (Thaler and Johnson, 1990) refers to the tendency for individuals to be more risk taking following prior gains and more risk averse following prior losses. There are less studies of the house money effect than the disposition effect in the finance literature, though there is emerging evidence of the former effect. Recent studies report evidence in support of a house money effect in range of settings; including individual investors in Sweden (Massa and Simonov, 2005), market-makers in the Taiwan futures exchange (Liu et al., 2010) and the Sydney Futures Exchange (Frino et al., 2008). In an empirical study using individual investor level-data, Duxbury et al. (2015) document that the disposition and house money effects can contemporaneously coexist in a single stock market, that the majority of 
investors simultaneously succumb to both effects and, furthermore, that the house money effect moderates the disposition effect, thus cognitive biases need not always have negative consequences on behavior.

Empirical examination of the impact of prior outcomes on investor behavior based on real trading data may prove problematic. In accordance with rational economic models, observed trading behavior might be driven more by investors' expectations concerning future prices/returns, which are unobservable and uncontrollable, than by the influence of prior outcomes. The experimental method is ideally suited to isolating the impact of prior outcomes on trading behavior, while controlling or manipulating future expectations. Indeed, there is ample experimental evidence demonstrating the existence of the disposition effect. Weber and Camerer (1998) carry out the earliest experimental examination of the disposition effect. Participants buy and sell risky assets with prices determined exogenously by a random process from period-to-period, thus controlling for investor expectations concerning future prices/returns. Differing probabilities of price increase/decrease produce assets with positive /neutral/negative trends. Weber and Camerer (1998) find evidence of a disposition effect analogous to that of Odean (1998a), with winning assets accounting for a greater proportion of sales than losing assets (60\% vs 40\%, respectively). Interestingly, they note that the disposition effect is weakened in a treatment condition with automatic selling at the end of some periods. If participants were not affected by prior outcomes, and made decisions based on expectations of future prices changes alone, then automatic selling should have no impact on the tendency to observe the disposition effect as participants are able to repurchase at the start of the next period shares automatically sold the previous period.

The experimental setting in Weber and Camerer (1998) has been replicated in a number of subsequent studies, all of which report evidence corroborating the presence of the disposition effect. Chui (2001), for example, examines the extent to which locus of control might explain the disposition effect, finding only partial support. Da Costa et al. (2008) examine the role of 
gender differences in the disposition effect, with the results dependent on the reference price adopted. Based on original purchase price, they find no difference across males and females, with both genders exhibiting a disposition effect. When the reference price is the last price paid, however, the results change; while males continue to exhibit a disposition effect, females do not. More recently, Rau (2014) examines gender differences in the context of the disposition effects and loss aversion. While the results show that both genders succumb to the disposition effect, the effect is more pronounced for females, with the difference driven by their greater reluctance to realize capital losses. Rau (2014) reports that females are more loss averse than males, with loss aversion negatively correlated with the propensity to realize capital losses, thus explaining gender differences in the disposition effect.

Summers and Duxbury (2012) also investigate the disposition effect in an experiment with exogenous prices, but in contrast to the above studies they use historic price sequences and examine the effect using a between-subjects design with participants assigned to a winner (positive price trend) or loser (negative price trend) condition. While they find evidence of a disposition effect when participants are responsible for the prior gains or losses, they fail to observe a disposition effect in a treatment condition where prior gains and losses are experienced, but responsibility is absent, thus calling into question the prospect theory explanation of the disposition effect routinely accepted in many prior empirical studies-an issue to which we return in the following section on moods and emotions.

Oehler et al. (2003) examine the disposition effect in experiments designed to test whether individual-level disposition effects attenuate or survive in a market setting in which prices are determined endogenously by the trades of participants. They contend that empirical studies suffer from the noise and incompleteness inherent in real data, while investors' expectations and executed individual decisions are rarely observed in naturalistic financial markets. ${ }^{1}$ In contrast, their experimental setting allows Oehler et al. (2003) to observe the whole trading process from

\footnotetext{
${ }^{1}$ While perhaps more relevant at the time of their study, there are a growing number of empirical studies that have
} access to and analyse investor-level transaction data. 
the order generation up to the endogenous price formation and order execution, all observed at both the market and investor level. In a series of stock markets, Oehler et al. (2003) find evidence of individual-level disposition effects with the majority of participants demonstrating a strong preference for realizing winners rather than losers. Their results are generally robust to the choice of trading mechanism and assumed reference price, though the disposition effect is greatly reduced in high-pressure mechanisms like a dealer market and when the last price is assumed as a reference point.

Brown and Kagel (2009) investigate the extent to which the disposition effect causes investors to deviate from optimal behavior. They employ a simple experimental setting in which participants hold only one stock at a time and can exchange stocks after every period in which prices change. Stock prices follow a known distribution, with identification of the optimal stock(s) relatively clear. In the experiment, investors obtain just over half of the increase in profits to be earned as a result of following an optimal investment strategy (53.4\%), with the shortfall primarily due to failure to compare returns on stock held to returns on the full set of available stocks. In contrast to other experimental studies, Brown and Kagel (2009) show that, providing participants compare their existing stock to the available choices, they do not succumb to the disposition effect and instead generally hold superior performing stocks while selling poorer performing stocks. While they fail to find a disposition effect, Brown and Kagel (2009) attribute this to the nature of the task facing participants. In their experiment, disposing of one stock for another does not trigger a realized capital gain or loss since stocks are exchanged on a one-for-one basis. The decision to sell a winner or hold a loser does not, therefore, promote the gain/loss framework of prospect theory commonly believed to underlie the disposition effect.

With the presence of the disposition effect established in experimental markets, more recent experimental studies have turned to consider how the effect might be attenuated. Following empirical findings that the disposition effect is heightened for inexperienced investors (e.g. Feng and Seasholes, 2005), Da Costa et al. (2013) examine the extent to which investing experience 
can reduce the disposition effect. They conduct stock market experiments with two groups of participants, stock investors with a minimum of 2 years of trading experience (experienced investors) and undergraduate students (inexperienced investors). A control market with robot traders making random buy/sell decisions did not exhibit a disposition effect, while both groups with human participants did. Da Costa et al. (2013) interpret this as evidence that the disposition effect must be rooted in some form of cognitive illusion rather than features of their experimental market. Their results also show, in line with prior empirical evidence, that more experienced investors exhibit lower levels of disposition effect.

Goals have been shown to be a key driver of a financial behavior (Antonides et al. 2011). From the perspective of goal systems theory, the disposition effect may be understood in the context of a winning stock's good performance being viewed as progress towards a sub-goal of obtaining financial returns, whereas a losing stock's poor performance can be interpreted as a lack of progress. Aspara and Hoffmann (2013) conjecture that activating a superordinate goal of financial savings, as opposed to the sub-goal of obtaining financial returns, might reverse a disposition to sell winning stocks and hold losing ones. To test this conjecture, they conduct three experiments in which they activate a superordinate savings goal in three different ways: i) a scrambled sentence priming task; ii) a prime to increases the salience of portfolio performance; iii) explicit reference to a superordinate savings goal with clear end point. All three treatment conditions were found to significantly reverse the disposition effect relative to a control condition. Hence, activating a superordinate (savings) goal can have wealth benefits as it promotes a reversal of the disposition effect.

Frydman and Rangel (2014) also investigate ways of debiasing the disposition effect in an experimental setting by manipulating the saliency of the purchase price. They find a disposition effect in a high-saliency condition, where purchase price is displayed, as is the norm in prior experiments, while the effect is reduced by $25 \%$ in a low-saliency condition, where purchase price is not displayed. Reducing the saliency of the purchase price can have wealth benefits by 
reducing the tendency to succumb to the disposition effect, however, even under such conditions individuals still exhibit suboptimal trading behavior (i.e. the disposition effect is not eliminated).

In addition to experimental evidence in relation to the disposition effect, there is some evidence of higher risk taking following prior gains consistent with a house money effect in experimental financial markets. While predominantly concerned with an examination of myopic loss aversion in the context of the equity premium puzzle, Gneezy et al. (2003) also test for the presence of the house money effect in their experimental data. They find a significant positive effect of lagged profits on asset expenditures; traders with a prior profits display a higher tendency to buy (lower tendency to sell) assets than traders with a prior loss. Given the risky nature of the assets traded, Gneezy et al. (2003) interpret these results in line with the house money effect (i.e. higher risk taking following prior gains than prior losses). They note, however, that the house money effect, which implies that sequential gambles are segregated (i.e. outcomes evaluated separately) rather than integrated (i.e. outcomes from successive gambles merged), is unable to explain price differentials across their treatment conditions investigating high and low frequency of portfolio adjustment and information feedback. This is because the average realized asset value was higher, and observed prices lower, in the high frequency than the low frequency treatment condition. Whereas the house money effect, based on increased risk taking following gains (i.e. higher realized asset values), would be expected to increase the price in the high frequency treatment condition.

In a purposefully designed experiment, Ackert et al. (2006) investigate the impact of the house money effect on asset pricing in multi-period markets. In each market eight participants compete via a sealed-bid auction to acquire a one-period lived asset with a randomly determined payout ( $\$ 0$ or $\$ 40$, with equal probability). The four highest bidders purchase the asset at the fifth highest bid price. For market prices between $\$ 0$ and $\$ 40$, wealth is negatively (positively) affected when the dividend is $\$ 0(\$ 40)$, both for individual traders and by extension the market 
as a whole, because half of all traders have their wealth affected while the other half experience no change. The treatment of interest in the experiment is the initial endowment of cash; high versus low. The results strongly support a persistent house money effect, with initial prices significantly higher in the high versus low endowment conditions, in line with increased risk seeking following prior gains. Given the seemingly contradictory risk taking behavior central to prospect theory (risk aversion/seeking in the gain/loss domains), the model of choice in many behavioral finance studies, both theoretical and empirical, and the outcome segregation in sequential decisions at the heart of the house money effect, the evidence in Ackert et al. (2006) suggests that caution may need to be exercised in applying the predictions from prospect theory, essentially a one-shot model, to a dynamic financial market; a challenge taken up by De Giorgi and Hens (2006).

\section{Moods and emotions}

Historically rooted in cognitive psychology (i.e. biases, heuristics and models of decision under risk), behavioral finance can benefit from insights drawn from the psychology of emotions (Elster, 1998). Rick and Loewenstein (2008) argue the consequentialist nature of economic models does not render them devoid of the influence emotions. Drawing a distinction between expected emotions and immediate emotions, with the latter further distinguished between integral and incidental emotions, they note that only incidental emotions, commonly referred to as moods in the psychology literature and elsewhere, represent a challenge to the rational economic view. As such, the distinction between mood and emotion is an important one to maintain, as acknowledged by Ackert et al. (2003) and Kramer (2014) for example, but one commonly blurred in the finance literature, either implicitly or explicitly. We maintain the distinction here, reviewing the experimental evidence in relation to the influence first of moods and then of emotions on financial behavior, discussing the findings from the empirical finance literature briefly in both cases. 
For a detailed discussion of the empirical literature examining the relationship between investor mood and equity returns, we direct the reader to Lucey and Dowling (2005), Shumway (2010) and Kramer (2014). Note, however, a common feature of the empirical approach is the use of psychology to motivate suitable proxies of unobservable investor mood. Common mood proxies employed in the literature include, among others, weather and temperature, biorhythms (daylight saving time changes, seasonal affective disorder, lunar phases) and sporting events. A number of studies document a significant relationship between weather-induced mood and equity market returns (e.g. Saunders, 1993; Hirshleifer and Shumway, 2003), though there is no evidence of an effect on individual investor behavior (e.g. Goetzmann and Zhu, 2005). Findings in Kamstra et al. $(2000,2003)$ suggest that mood effects associated with biorhythm variables such as changes in daylight saving time and the hours of daylight (associated with seasonal affective disorder), both of which are predictable, impact equity returns. Their results have been called into question, however, by a number of studies (e.g. Pinegar, 2002; Jacobsen and Marquering, 2008, 2009; Gerlach, 2010; Gregory-Allen et al. 2010), and a debate has ensued in the literature. The stock market reaction to changes in investor mood brought about by the outcomes of international sporting events has been documented in a number of studies (e.g. Ashton et al., 2003, 2011; Edmans et al., 2007). Their findings have been called into question, however, by studies re-examining their results using alternative statistical approaches (e.g. Klein et al., 2009; Fung et al., 2015). Dowling and Lucey (2008) search for a robust global mood proxy, examining the relationship between a range of mood-proxy variables and a global equity dataset. They conclude that seasonal affective disorder and low temperatures exhibit the greatest relationship with equity pricing.

We do not wish to become embroiled in discussions in the literature concerning the validity or otherwise of weather, biorhythm or sporting effects on stock market returns, but note that such debates serve to strengthen the need for experimental studies to examine the impact of mood on investor behavior and financial markets in controlled laboratory settings, in which 
investor mood can be observed directly or manipulated. In foreign exchange trading experiments with historic data, Au et al. (2003) manipulate investor mood via feedback, music and/or mood-laden statements, thus priming good, bad or neutral mood. They report that badmood traders were most accurate in their decisions, but conservative in their trading, while goodmood traders made less accurate decisions, despite spending a similar amount of time on information processing and decision-making, and were over-confident taking higher risks. The trading performance of good-mood traders was inferior to that of other traders.

The impact of integral emotions is a less researched area than incidental mood. In a notable early study, Lo and Repin (2002) examine the emotional responses of professional securities traders by measuring changes in physiological arousal (e.g., skin conductance, blood volume pulse, etc.) during actual trading, while capturing real-time prices data. They find statistically significant differences in emotional responses during transient market events and periods of increased market volatility, suggesting that trading outcomes can trigger integral emotions. Experimental evidence suggests integral emotions, in particular regret, play a role in financial decisions, including escalation of commitment (sunk cost effect) and the disposition effect, to which we now turn.

Prospect theory has been advanced as a cognition-based explanation of the sunk cost effect or escalation of commitment (Whyte, 1986), with prior losses inducing increased risk seeking and associated escalation behavior. Drawing on the differential risk taking behavior predicted by prospect theory's S-shaped value function, Duxbury (2012) examines experimentally the prospect theory explanation by manipulating whether an initial investment produces a sunk cost (loss) or a sunk benefit (gain). Contrary to the predictions of prospect theory, the results fail to support a higher likelihood of investing following a sunk cost than a sunk benefit. In isolation, therefore, prospect theory is unable to explain fully the sunk cost effect and other studies have examined the role of specific emotions, namely regret. Experimental evidence in relation to anticipated regret is mixed, with Wong and Kwong (2007) finding a relationship between 
anticipated regret and escalation, while $\mathrm{Ku}$ (2008a) does not, due to individuals underestimating how much they would escalate. Switching attention to experienced regret, however, $\mathrm{Ku}(2008 \mathrm{~b})$ finds that the higher an individual's post-escalation regret in one task (anagram), the lower their escalation in a second subsequent task (dollar auction). Post-escalation regret, even in an unrelated task, can help to reduce escalation behavior in a subsequent auction, thus suggesting a role for emotions in such behavior.

In an empirical examination of the disposition effect, Lehenkari (2012) compares predictions based on prospect theory, escalation of commitment and belief in mean reversion, using a dataset in which it is possible to distinguish between stocks that investors buy themselves and those they receive via inheritance/gift. Lehenkari (2012) reports that investors tend to hold losers received via inheritance/gift less than the losers they were responsible for purchasing. Regret is an emotion linked to responsibility (Zeelenberg et al., 1998), hence the empirical evidence suggests an anticipated regret driven escalation of commitment-based explanation for the tendency to hold losers in the disposition effect. Despite the novelty of the dataset in Lehenkari (2012), it is only possible to infer the role of regret, because manipulation and/or direct measurement of investors' emotions are not possible. Summers and Duxbury (2012) demonstrate experimentally that emotions play a causal role in the tendency to succumb to the disposition effect. In their experiment they manipulate responsibility for prior gains and losses, which in turn manipulates the emotions to be experienced. Absent responsibility for the initial investment decision, prior gains/losses prompt feelings of elation/disappointment ${ }^{2}$ at the outcome, while feelings of rejoicing/regret may also be experienced where responsibility is present. Summers and Duxbury (2012) show that regret drives the tendency for investors to hold losers, while elation is sufficient to cause investors to sell winners (rejoicing is not required). In the absence of responsibility for the initial investment decision, they find no evidence of a disposition effect in the presence of prior gains and losses, thus providing direct support for

\footnotetext{
2 Elation and disappointment are experienced as a result of an observed outcome, while regret and rejoicing are triggered by making a decision that lead to the observed outcome and thus require choice to be present.
} 
theoretical (Barberis and Xiong, 2009) and empirical (Kaustia, 2010; Lehenkari, 2012) challenges to the view that prospect theory provides a sole causal explanation.

In an empirical study of repurchase decisions, Strahilevitz et al. (2011) report that investors are reluctant to repurchase stocks previously sold at a loss or that have risen in price subsequent to a prior sale. Their emotion-based explanation draws on Summers and Duxbury's (2012) theorizing regarding the role of emotions in the disposition effect. Strahilevitz et al. (2011) purport the behavior they observe to be driven by counterfactual thinking and the associated feelings of regret and disappointment, though, as they acknowledge, their use of field data prevent them from determining the underlying psychological mechanisms definitively. Frydman and Camerer (2015) use neural data combined with trading data obtained in an experiment to illuminate the repurchase behavior observed in Strahilevitz et al. (2011). They test a regretdevaluation model in which an observed price increase for a previously sold stock causes an investor to experience regret, thus decreasing the expected utility derived from repurchasing the stock. Frydman and Camerer (2015) report empirical results based on their neural data that are largely consistent with this regret-based explanation. Frydman and Camerer (2015) go further, investigating whether the disposition effect (selling behavior) and repurchase effect (buying behavior) are driven by a common psychological mechanism. In support of this view they document significant correlations across participants in their study both between measures of the disposition effect and repurchase effect and also between the neural signals that stimulate them.

In summary, the experimental findings in Summers and Duxbury (2012) and Frydman and Camerer (2015) suggest that experienced regret has a strong role to play in the disposition effect and repurchase effect, and trading behavior generally.

A second emotion that has been examined in the context of investment behavior is fear, as epitomized by Shefrin's (2000) book, Beyond Greed and Fear. Kaplanski and Levy (2010) empirically examine what could be construed as an extreme mood proxy, large-scale aviation disaster, to test the assertion that emotionally charged media coverage of such events increases 
investor fear and anxiety, which in turn negatively affects stock prices. They report an immediate and dramatic negative overreaction to such events, followed by an almost complete price reversal over the course of a few days post event. Unable to find support for a rational explanation, they conclude that fear and anxiety among investors, fuelled by emotionally charged media coverage of the event, is at the heart of the reaction.

Turning to consider experimental evidence, Tsai and Young (2010) investigate the impact of fear, along with anger, in the context of escalation of commitment. In a two-stage experiment, emotions are first induced via a recall task and then an escalation task (financial decisions or personnel hiring) is completed. Hence, while fear is an immediate emotion, in contrast to regret which is integral in $\mathrm{Ku}(2008 \mathrm{a}, \mathrm{b})$, fear is incidental in the experimental design of Tsai and Young (2010). They find that fear resulted in higher risk perception and reduced tendency to escalate than was observed for anger. Bosman and Van Winden (2010) examine the influence of social moods, specifically fear associated with international terrorism or political risks, which is expected to promote risk aversion. In a repeated trials risky choice task, participants in a "global risk" condition are exposed to the probability of losing their earnings at the end of the experiment (risk of expropriation). Relative to a control condition, tendency to select the risky option was lower, in line with fear heightening the degree of risk-aversion.

The role of fear in financial behavior is further examined in a series of experiments by Lee and Andrade $(2011,2015)$. In both papers, fear is induced in participants and so is an incidental emotion. Noting that specific emotions trigger specific action tendencies, Lee and Andrade (2011) investigate the impact of incidental fear on selling behavior and find a tendency for participants to sell their stock earlier in the presence of incidental fear than under control conditions where fear is not induced. While this is true when participants believe their risk attitude is common among other market participants, it does not hold when they believe their risk attitude is unique, which Lee and Andrade (2011) explain in the context of social projection. In the former case, fearful participants want to sell and predict others will feel the same, thus 
prompting earlier sell decisions in anticipation of a fall in value, while in the latter case, although fearful participants want to sell, they predict others will not, thus prompting later sell decisions in anticipation of increasing value.

Lee and Andrade (2015) further explore the role of fear, commonly associated with pessimistic judgement and risk-aversion, in financial behavior, examining conditions under which fear may promote or discourage risk-taking. They note that fear is a highly arousing emotion associated with uncertainty (or danger) and negative hedonic tones, while other highly arousing uncertainty-associated emotions, such as excitement, have positive hedonic tones. Given that fear and excitement share two emotional components (high arousal and high uncertainty), Lee and Andrade (2015) suggest it is plausible that what is scary can become exciting as a result of contextual cues, leading to the possibility that differences in risk attitude driven by fear or excitement result in changes in behavior. To this end, they induce fear (vs. no-fear control) and then ask participants to make financial decisions in a task framed either as a stock market investment or an exciting casino-based gamble. While incidental fear induced risk-averse behavior when the financial task was framed as an investment, it encouraged risk-taking when framed as a casino-based gamble. Results in Lee and Andrade (2015), therefore, demonstrate that fear, reinterpreted as excitement, may promote rather than discourage risk-taking behavior, suggesting a different response between those traders that are excited by investing in the stock market and those that are not.

Reminiscent of the empirical approach in Lo and Repin (2002), the experiments of Nguyen and Noussair (2014) examine emotional responses during risky decision making, monitoring facial expressions using a face reading software that measures the degree of conformity with a number of emotions, among them fear (others are happiness, anger, disgust, surprise and sadness). By observing emotional response during the risky choice task, Nguyen and Noussair (2014) examine integral emotions, and in particular integral fear. They find that the level of fear experienced in the face of risky choices (as captured by facial expressions) correlates with the 
extent of risk-averse behavior in subsequent choices. More generally, they conclude, the stronger the emotional response (fear, anger, happiness and surprise), the more risk-averse the behavior. They also find positive emotional valence is associated with increased risk tolerance, consistent with the notion that positive emotions promote risk taking.

Using the same approach, Breaban and Noussair (2013) examine the influence of emotions, measured by facial expressions, on trader behavior in asset markets known to induce bubbles and crashes. They find positive emotions to be associated with higher prices/bubbles, with individuals in heightened positive emotional states tending to buy more during the boom phase of a bubble. During the collapse of the bubble, however, there is a strong relationship between anger and the magnitude of loss. Fear, furthermore, is strongly correlated with the degree of loss aversion an individual exhibits. Breaban and Noussair (2013) provide evidence, therefore, to confirm the belief that integral emotions have a fundamental role to play in the irrational exuberance that drives bubbles and crashes (Shiller, 2005).

Andrade et al. (2015) also examine the role of emotions in bubbles and crashes. They do so, however, using video clips to induce excitement, neutrality, fear or sadness, hence they are concerned with incidental emotions and their findings have more in common with studies of mood discussed above. Andrade et al. (2015) find that induced excitement is associated with larger bubbles, while the other three induced conditions, including incidental fear, do not differ from each other. The difference in results in relation to the role of fear in bubbles and crashes across Andrade et al. (2015) and Breaban and Noussair (2013) serves to further heighten the importance of distinguishing between incidental and integral emotions.

Returning to a topic covered in the companion review paper, Duxbury (2015), we briefly consider experimental evidence of the role of emotion in relation to myopic loss aversion and the equity premium puzzle. In a 20-round, positive expected value investment task closely modelled on Gneezy and Potters (1997), Shiv et al. (2005) compare the decisions of patients with brain lesions in regions associated with emotion (target participants) with patients with brain 
lesions in regions unrelated to emotion, as well as normal participants. Examining the extent to which decision-outcomes in preceding rounds affected decisions (invest or not invest) in subsequent rounds, Shiv et al. (2005) find that target participants are less affected than the other two control groups, being less likely to reduce their risk-taking irrespective of whether they won or lost in the previous round. Hence, given the positive-expected-value gambles, Shiv et al. (2005) conclude that target participants (with impaired emotional response to financial outcomes) experience less myopic loss aversion and make more advantageous decisions than the other two groups (i.e. those with emotional impairment). The experimental evidence in Shiv et al. (2005) linking the role of emotion to the equity premium puzzle is supported by the link between fear and loss aversion demonstrated in Breaban and Noussair (2013) and is further complemented by the empirical findings in Fielding and Stracca (2007) suggesting a role for disappointment aversion in explaining the puzzle.

Moving away from specific emotions, a number of studies examine the broader concept of affect, a valenced feeling state defined as "the experience a person has in response to a stimulus" (Ackert and Deaves, 2009, p122). Knewtson and Sias (2010), for example, investigate the letter name effect in security selection. Indirect empirical analysis of institutional stock holdings shows that the number of institutions holding a given stock is greater for firms whose names begin with more common name letters. In a study of student stock recommendations, which provides a more direct test of the letter name effect, Knewtson and Sias (2010, p1327) find that students exhibit a "preference for recommending securities that begin with their own first name initial or either their first or last name initial." They conclude that investors' stock selection decisions are related to emotional or affective stimuli and not solely due to rational factors associated with valuation. In a series of experiments, Ackert and Church (2006) provide further direct evidence that investment decisions are influenced by affective (i.e., emotional) reactions, with participants investing more in positive-image firms than negative-image firms, this despite the fact that information conveyed concerning firm image had no bearing on valuation. The finding suggests 
that investor stock selection might be driven, at least in part, by whether they "like" a firm and not solely down to its valuation.

Affective attitude has also been shown to play a role in fundamental principles of finance theory, linking back to one of the themes of the first review paper, Duxbury (2015). In an experimental examination of the impact of affective attitudes on the risk-return relationship, Kempf et al. (2014) ask participants to forecast risk and return for well-known blue-chip firms and to rate them on a semantic differential scale to measure affective attitudes. They employ four 7-point scales ranging from good-to-bad, interesting-to-boring, strong-to-weak, and activeto-passive. Irrespective of whether affective ratings are elicited before or after the risk and return estimation, Kempf et al. (2014) report that positive affective attitudes produce predictions of high return and low risk, and vice versa for negative affective attitudes. Their findings are in stark contrast to the assumed positive risk-return relationship of finance theory.

\section{Conclusions and discussion}

Jointly, this paper and the companion paper (Duxbury, 2015), demonstrate the valuable contribution made by experimental studies in extending our knowledge and understanding of the functioning of financial markets and the financial behavior of individuals. Given the vast number of economic and psychology experimental studies that could inform such a discussion, there is a clear need to be selective. In the companion paper we focus on those studies that test, either explicitly or inform directly, empirically observed anomalies associated with portfolio theory and diversification decisions, equity premium puzzle, herding and financial contagion, along with other stylized facts associated with return distributions. In this paper we examine the contribution of experimental studies to our understanding of heuristics and biases at the heart of behavioral models (e.g. under/overreaction, overconfidence) and observed investor behavior (e.g. the impact of prior outcomes), along with the influence of moods and emotions on financial behavior. 
A key strength of the experimental method over empirical field-based research is the ability to measure directly, and afford a greater degree of control over, variables predicted or otherwise to impact on financial behavior (see Bloomfield and Anderson, 2010, for a detailed discussion). In addition to the examples reviewed in Duxbury (2015), this paper provides a wealth of additional examples to further support this claim. In the context of under/overreaction, a strength of the experimental approach is the ability to identify, and manipulate, the fundamental value of the traded asset. The importance of this is well demonstrated by Lin and Rassenti (2012). In an examination of return autocorrelations, as is standard in field-based research, they observe that examining continuation/reversal of return signs fails to consistently indicate true under/overreaction, after taking account of fundamentals, thus casting doubt on the validity of field-based findings reliant on such an empirical approach. Also in the context of under/overreaction, the experimental approach allows the direct testing of assumptions underpinning behavioral models that would not be possible otherwise; for example, Rotheli (2011) observes that expectations elicited in the experiment cannot be explained by the Bayesian probability updating at the heart of the Barberis et al. (1998) model.

While behavioral finance models almost exclusively adopt miscalibraton as their overconfidence measure of choice, Biais et al. (2005) and Glaser and Weber (2007) fail to find a relationship between overconfidence (miscalibration) and trading volume, a common overconfidence proxy in the field-based literature. Furthermore, Biais et al. (2005) find no correlation between overconfidence (miscalibration) and gender, another common overconfidence proxy. Experimental evidence suggests, therefore, that the use of proxies in empirical studies of the effect of overconfidence on financial behavior may be problematic. Miscalibration is only one form of overconfidence and others have been proposed such as the better-than-average effect ('referential' overconfidence) and the difference between objective accuracy and subjective certainty. A number of experimental studies examining the degree of correlation between overconfidence measures report little correlation between the different 
measures of overconfidence, along with inconsistent results across the measures (e.g. Kirchler and Maciejovsky, 2002; Glaser and Weber, 2007; Acker and Duck, 2008; Deaves et al., 2009). Such inconsistent results are problematic for the finance literature. Many studies assume, either explicitly or implicitly, that the different types of overconfidence are the same and this is true of the key behavioral models in the finance literature (e.g. Barber and Odean, 2001; Daniel et al., 1998; Odean, 1998b). Future theoretical models of overconfidence would benefit from greater clarity and precision in regard to the definitions and measures of overconfidence they employ. Furthermore, evidence in Kaustia and Perttula (2012) indicating that different types of overconfidence respond differentially to debiasing techniques, serves to lend weight to the need for greater clarity and precision from a policy/intervention perspective too.

The experimental method is ideally suited to isolating the impact of prior outcomes on trading behavior, while controlling or manipulating future expectations, which is problematic in field-based empirical studies. Initial experiments document the presence of the disposition effect (e.g. Weber and Camerer, 1998) and the house money effect (e.g. Ackert et al., 2006), while more recent experiments investigate the drivers of such behavior (e.g. Summers and Duxbury, 2012) and potential interventions designed to attenuate or debias such effects (e.g. Aspara and Hoffmann, 2013; Frydman and Rangel, 2014).

There are a growing number of empirical studies examining the correlation between investor mood and equity market returns, a common feature of which is the use of psychology-based proxies of the unobservable investor mood (e.g. weather, biorhythms and sporting events). The use of such proxies is not without problem, however, and debates have developed in the literature discussing the validity of results reported in such studies. In contrast, experiments allow the direct measurement and/or manipulation of moods and emotions, both incidental and integral, thus providing causal evidence of their influence on financial decisions and trading behavior, ranging from regret $(\mathrm{Ku}, 2008 \mathrm{a}, \mathrm{b})$ and fear (Tsai and Young, 2010) in the escalation of commitment, to regret and elation in the disposition effect (Summers and Duxbury, 2012) and 
fear in the equity premium puzzle (Shiv et al., 2005; Breaban and Noussair, 2013). While regret, for example, has long been discussed as a potential determinant of trading behavior (Shefrin and Statman, 1985), it is only recently that experiments by Summers and Duxbury (2012) and Frydman and Camerer (2015), for example, provide conclusive evidence that integral regret has a strong role to play in the disposition effect and repurchase effect, and hence selling and buying behavior generally. Breaban and Noussair (2013) provide experimental evidence to confirm integral emotions have a fundamental role to play in the irrational exuberance that drives bubbles and crashes (Shiller, 2005), while Andrade et al. (2015) show that incidental emotions have a role to play in such stylized facts too. To reiterate, the need to rely on the use of proxies in fieldbased empirical studies render such definitive, causal conclusions with regard to the role of incidental and integral emotions impossible.

Fama (1998) is critical of the lack of guiding conceptual framework in behavioral finance and the seemingly ad hoc reliance on a range of, sometimes contradictory, psychological explanations of observed behavior. Durand et al. (2013) cite momentum as a case in point, with explanations in the literature ranging from underreaction to overreaction, the disposition effect to selfattribution bias and overconfidence. The view is echoed by Raghubir and Das (1999), who note the empirical literature offers a multitude of explanations of behavioral anomalies, but who advocate the use of theory-driven experiments to distinguish between competing explanations and to complement existing empirical approaches. Hirshleifer (2015, p.43), too, acknowledges that "building a financial model by just assuming some behavior that seems plausible, or even by invoking a documented psychological bias, is not always compelling" due to the vast array of behavioral biases to choose from, concluding that a "healthy nascent trend in behavioral economics and finance has been to run laboratory and field experiments that closely match the decision environment assumed in the financial model".

Key psychological building blocks permeating many behavioral finance models and empirical studies are prospect theory and mental accounting. These have been central to explanations of 
many anomalies and observed biases/behaviors, including the equity premium puzzle, disposition effect and escalation of commitment. Indeed, prospect theory "is one of the-if not the-most prominent descriptive theories of decision making under uncertainty [risk]" (Arkes et al., 2010, p. 99). In his thirty-year retrospective on prospect theory in economics, Barberis (2013) notes that finance is the field where prospect theory has been most actively, and perhaps effectively, employed, despite the challenges associated with defining gains and losses relative to reference points. An important message that we take from this two-part review of the experimental evidence concerning individual financial behavior and the functioning of financial markets, however, is that prospect theory's all reaching effect is beginning to be challenged, e.g. in relation to equity premium puzzle, disposition effect and escalation of commitment.

Behavioral finance may have to cast its net wider in the psychology literature to reduce its dependence on prospect theory. Indeed, Altman (2010, p.192) acknowledges that prospect theory "touches on only a subset of issues raised in the behavioral finance literature". A fruitful line of enquiry already reaping benefits is to examine further the role of integral emotions in financial decisions, thus providing a deeper understanding of individual behavior (for example, the role of regret and elation in the disposition effect-Summers and Duxbury, 2012) and the stylized facts of financial markets (for example, the role of positive (e.g. surprise) and negative (e.g. fear) emotions in bubbles and crashes-Breaban and Noussair, 2013). While studying integral emotions in field-based empirical research represents a challenge, the experimental method is well suited; providing the opportunity to measure, manipulate and control integral emotions in investigations of the causal role they play in financial behavior.

To conclude, the experimental method is well established in finance and is well placed to make further significant contributions to the behavioral finance literature, continuing to advance our understanding of individual financial behavior and the functioning of financial markets. 


\section{References}

Acker, D., and Duck, N.W. (2008). Cross-cultural overconfidence and biased self-attribution. The Journal of Socio-Economics, 37(5), 1815-1824.

Ackert, L.F., Church, B.K., and Deaves, R. (2003). Emotion and financial markets. Economic Review-Federal Reserve Bank of Atlanta, 88(2), 33-42.

Ackert, L.F., Charupat, N., Church, B.K., and Deaves, R. (2006). An experimental examination of the house money effect in a multi-period setting. Experimental Economics, 9(1), 5-16.

Ackert, L.F., and Church, B.K. (2006). Firm image and individual investment decisions. The Journal of Behavioral Finance, 7(3), 155-167.

Ackert, L.F., and Deaves, R. (2009). Behavioral finance: Psychology, decision-making, and markets. Cengage Learning, Mason, United States.

Altman, M. (2010). Prospect theory and behavioral finance. In Baker H.K. and Nofsinger, J.R. (Eds.) Behavioral Finance: Investors, Corporations, and Markets, Chapter 11, 191-209. John Wiley \& Sons, Inc., Hoboken, NJ, USA.

Andrade, E.B., Odean, T., and Lin. S. (2015). Bubbling with excitement: An experiment. Review of Finance, Advance Access, doi: 10.1093/rof/rfv016.

Antonides, G., de Groot, I.M., and van Raaij, W.F. (2011). Mental budgeting and the management of household finance. Journal of Economic Psychology, 32(4), 546-555.

Arkes, H.R., Hirshleifer, D., Jiang, D., and Lim, S.S. (2010). A cross-cultural study of reference point adaptation: Evidence from China, Korea, and the US. Organizational Behavior and Human Decision Processes, 112(2), 99-111.

Ashton, J.K., Gerrard, B., and Hudson, R. (2003). Economic impact of national sporting success: evidence from the London stock exchange. Applied Economics Letters, 10(12), 783-785.

Ashton, J.K., Gerrard, B., and Hudson, R. (2011). Do national soccer results really impact on the stock market? Applied Economics, 43(26), 3709-3717. 
Aspara, J., and Hoffmann, A.O. (2013). Selling losers and keeping winners: How (savings) goal dynamics predict a reversal of the disposition effect. Marketing Letters, 26(2), 201-211.

Asparouhova, E., Hertzel, M., and Lemmon, M. (2009). Inference from streaks in random outcomes: Experimental evidence on beliefs in regime shifting and the law of small numbers. Management Science, 55(11), 1766-1782.

Au, K., Chan, F., Wang, D., and Vertinsky, I. (2003). Mood in foreign exchange trading: Cognitive processes and performance. Organizational Behavior and Human Decision Processes, 91(2), 322-338.

Barber, B.M., and Odean, T. (2000). Trading is hazardous to your wealth: The common stock investment performance of individual investors. Journal of Finance, 55(2), 773-806.

Barber, B.M., and Odean, T. (2001). Boys will be boys: Gender, overconfidence, and common stock investment. Quarterly Journal of Economics, 116(1), 261-292.

Barberis, N. (2013). Thirty Years of Prospect Theory in Economics: A Review and Assessment. Journal of Economic Perspectives, 27(1), 173-96.

Barberis, N., Shleifer, A., and Vishny, R. (1998). A model of investor sentiment. Journal of Financial Economics, 49(3), 307-343.

Barberis, N. and Xiong, W. (2009). What Drives the Disposition Effect? An Analysis of a Longstanding Preference-based Explanation. Journal of Finance, 64(2) 751-784.

Biais, B., Hilton, D., Mazurier, K., and Pouget, S. (2005). Judgemental overconfidence, selfmonitoring, and trading performance in an experimental financial market. The Review of Economic Studies, 72(2), 287-312.

Bloomfield, R. J., and Anderson, A. G. (2010). Experimental finance. In Baker H.K. and Nofsinger, J.R. (Eds.) Behavioral Finance: Investors, Corporations, and Markets, Chapter 7, 113130. John Wiley \& Sons, Inc., Hoboken, NJ, USA.

Bloomfield, R., Libby, R., and Nelson, M.W. (2000). Underreactions, overreactions and moderated confidence. Journal of Financial Markets, 3(2), 113-137. 
Bloomfield, R., and Hales, J. (2002). Predicting the next step of a random walk: experimental evidence of regime-shifting beliefs. Journal of Financial Economics, 65(3), 397-414.

Bloomfield, R.J., Tayler, W.B., and Zhou, F.H. (2009). Momentum, reversal, and uninformed traders in laboratory markets. Journal of Finance, 64(6), 2535-2558.

Bosman, R., and Van Winden, F. (2010). Global risk, investment and emotions. Economica, 77(307), 451-471.

Breaban, A., and Noussair, C.N. (2013). Emotional state and market behavior. CentER Discussion Paper Series No. 2013-031. Available at SSRN: http://ssrn.com/abstract=2276905 or http://dx.doi.org/10.2139/ssrn.2276905

Brown, A.L., and Kagel, J.H. (2009). Behavior in a simplified stock market: the status quo bias, the disposition effect and the ostrich effect. Annals of Finance, 5(1), 1-14.

Chen, G., Kim, K.A., Nofsinger, J.R., and Rui, O.M. (2007). Trading performance, disposition effect, overconfidence, representativeness bias, and experience of emerging market investors. Journal of Behavioral Decision Making, 20(4), 425-451.

Chuang, W.I., and Lee, B.S. (2006). An empirical evaluation of the overconfidence hypothesis. Journal of Banking and Finance, 30(9), 2489-2515.

Chui, P.M. (2001). An experimental study of the disposition effect: Evidence from Macau. Journal of Psychology and Financial Markets, 2(4), 216-222.

Da Costa Jr, N., Mineto, C., and Da Silva, S. (2008). Disposition effect and gender. Applied Economics Letters, 15(6), 411-416.

Da Costa Jr, N., Goulart, M., Cupertino, C., Macedo, J., and Da Silva, S. (2013). The disposition effect and investor experience. Journal of Banking and Finance, 37(5), 1669-1675.

Daniel, K., Hirshleifer, D., and Subrahmanyam, A. (1998). Investor psychology and security market under-and overreactions. Journal of Finance, 53(6), 1839-1885.

Deaves, R., Lüders, E., and Luo, G.Y. (2009). An Experimental Test of the Impact of Overconfidence and Gender on Trading Activity. Review of Finance, 13(3), 555-575. 
De Giorgi, E., and Hens, T. (2006). Making prospect theory fit for finance. Financial Markets and Portfolio Management, 20(3), 339-360.

DeBondt, W.F., and Thaler, R.H. (1985). Does the stock market overreact? Journal of Finance, 40(3), 793-805.

Dittrich, D.A., Güth, W., and Maciejovsky, B. (2005). Overconfidence in investment decisions: An experimental approach. European Journal of Finance, 11(6), 471-491.

Dowling, M., and Lucey, B.M. (2008). Robust global mood influences in equity pricing. Journal of Multinational Financial Management, 18(2), 145-164.

Durand, R., Newby, R., Tant, K., and Trepongkaruna, S. (2013). Overconfidence, overreaction and personality. Review of Behavioral Finance, 5(2), 104-133.

Duxbury, D. (2012). Sunk costs and sunk benefits: A re-examination of re-investment decisions. The British Accounting Review, 44(3), 144-156.

Duxbury, D. (2015). Behavioral Finance: Insights from experiments I: Theory and financial markets. Review of Behavioral Finance, 7(1), 78-96.

Duxbury, D., and Summers, B. (2004). Financial risk perception: Are individuals variance averse or loss averse? Economics Letters, 84(1), 21-28.

Duxbury, D., Hudson, R., Keasey, K., Yang, Z., and Yao, S. (2015). Do the disposition and house money effects coexist? A reconciliation of two behavioral biases using individual investor-level data. Journal of International Financial Markets, Institutions and Money, 34, 55-68.

Edmans, A., Garcia, D., and Norli, Ø. (2007). Sports sentiment and stock returns. Journal of Finance, 62(4), 1967-1998.

Elster, J. (1998). Emotions and economic theory. Journal of Economic Literature, 36(1), 47-74.

Fama, E.F. (1998). Market efficiency, long-term returns, and behavioral finance. Journal of Financial Economics, 49(3), 283-306.

Fellner, G., Güth, W., and Maciejovsky, B. (2004). Illusion of expertise in portfolio decisions: an experimental approach. Journal of Economic Behavior and Organization, 55(3), 355-376. 
Feng, L., and Seasholes, M.S. (2005). Do investor sophistication and trading experience eliminate behavioral biases in financial markets? Review of Finance, 9(3), 305-351.

Frino, A., Grant, J., and Johnstone, D. (2008). The house money effect and local traders on the Sydney Futures Exchange. Pacific-Basin Finance Journal, 16(1), 8-25.

Fielding, D., and Stracca, L. (2007). Myopic loss aversion, disappointment aversion, and the equity premium puzzle. Journal of Economic Behavior and Organization, 64(2), 250-268.

Frydman, C. and Camerer, C. (2015). Neural evidence of regret and its implications for investor behavior (April 28, 2015). Available at SSRN: http://ssrn.com/abstract=2600287 or http://dx.doi.org/10.2139/ssrn.2600287

Frydman, C., and Rangel, A. (2014). Debiasing the disposition effect by reducing the saliency of information about a stock's purchase price. Journal of Economic Behavior and Organization, 107 Part B, 541-552.

Fung, K. W. T., Demir, E., Lau, C. K. M., \& Chan, K. H. (2015). Reexamining sports-sentiment hypothesis: Microeconomic evidences from Borsa Istanbul. Journal of International Financial Markets, Institutions and Money, 34, 337-355.

Gerlach, J.R. (2010). Daylight and investor sentiment: A second look at two stock market behavioral anomalies. Journal of Financial Research, 33(4), 429-462.

Gervais, S., and Odean, T. (2001). Learning to be overconfident. Review of Financial studies, 14(1), $1-27$.

Glaser, M., and Weber, M. (2007). Overconfidence and trading volume. Geneva Risk and Insurance Review, 32(1), 1-36.

Gneezy, U., Kapteyn, A., and Potters, J. (2003). Evaluation periods and asset prices in a market experiment. Journal of Finance, 58(2), 821-838.

Gneezy, U., and Potters, J. (1997). An Experiment on Risk Taking and Evaluation Periods. Quarterly Journal of Economics, 112(2), 631-645. 
Goetzmann, W.N., and Kumar, A. (2008). Equity portfolio diversification. Review of Finance, 12(3), 433-463.

Goetzmann, W.N., and Zhu, N. (2005). Rain or shine: where is the weather effect?. European Financial Management, 11(5), 559-578.

Gregory-Allen, R., Jacobsen, B., and Marquering, W. (2010). The Daylight Saving Time Anomaly in Stock Returns: Fact or Fiction?. Journal of Financial Research, 33(4), 403-427.

Grinblatt, M., and Keloharju, M. (2001). What makes investors trade? Journal of Finance, 56(2), 589-616.

Hirshleifer, D. (2001). Investor psychology and asset pricing. Journal of Finance, 56(4), 1533-1597.

Hirshleifer, D. (2015). Behavioral Finance. Annual Review of Financial Economics, 7, forthcoming December 2015. Doi: 10.1146/annurev-financial-092214-043752.

Hirshleifer, D., and Shumway, T. (2003). Good day sunshine: Stock returns and the weather. The Journal of Finance, 58(3), 1009-1032.

Hoelzl, E., and Rustichini, A. (2005). Overconfident: Do You Put Your Money On It? The Economic Journal, 115(503), 305-318.

Hong, H., and Stein, J.C. (1999). A unified theory of underreaction, momentum trading, and overreaction in asset markets. Journal of Finance, 54(6), 2143-2184.

Jacobsen, B., and Marquering, W. (2008). Is it the weather? Journal of Banking and Finance, 32(4), 526-540.

Jacobsen, B., and Marquering, W. (2009). Is it the weather? Response. Journal of Banking and Finance, 33(3), 583-587.

Jegadeesh, N., and Titman, S. (1993). Returns to buying winners and selling losers: Implications for stock market efficiency. Journal of Finance, 48(1), 65-91.

Jordan, D., and Diltz, J.D. (2004). Day traders and the disposition effect. Journal of Behavioral Finance, 5(4), 192-200. 
Kahneman, D., and Tversky, A. (1982). The psychology of preferences. Scientific American, 246(1), 160-173.

Kamstra, M.J., Kramer, L.A., and Levi, M.D. (2000): Losing sleep at the market: The daylight saving anomaly. American Economic Review, 90(4), 1000-1005.

Kamstra, M.J., Kramer, L.A., and Levi, M.D. (2003). Winter Blues: A SAD Stock Market Cycle. American Economic Review, 93(1), 324-343.

Kaplanski, G., and Levy, H. (2010). Sentiment and stock prices: The case of aviation disasters. Journal of Financial Economics, 95(2), 174-201.

Kaustia, M. (2010). Prospect theory and the disposition effect. Journal of Financial and Quantitative Analysis, 45(3), 791-812.

Kaustia, M. and Perttula, M. (2012). Overconfidence and Debiasing in the Financial Industry. Review of Behavioral Finance, 4(1), 46-8.

Kempf, A., Merkle, C., and Niessen-Ruenzi, A. (2014). Low risk and high return-affective attitudes and stock market expectations. European Financial Management, 20(5), 995-1030.

Kilka, M., and Weber, M. (2000). Home bias in international stock return expectations. Journal of Psychology and Financial Markets, 1(3-4), 176-192.

Kim, K.A., and Nofsinger, J.R. (2003). The behavior and performance of individual investors in Japan. Pacific Basin Finance Journal, 11(1), 1-22.

Kirchler, E., and Maciejovsky, B. (2002). Simultaneous over-and underconfidence: Evidence from experimental asset markets. Journal of Risk and Uncertainty, 25(1), 65-85.

Klein, C., Zwergel, B., and Henning Fock, J. (2009). Reconsidering the impact of national soccer results on the FTSE 100. Applied Economics, 41(25), 3287-3294.

Knewtson, H.S., and Sias, R.W. (2010). Why Susie owns Starbucks: The name letter effect in security selection. Journal of Business Research, 63(12), 1324-1327. 
Kramer, L.A. (2014). Human Psychology and Market Seasonality. In Baker H.K. and Ricciardi, V. (Eds.) Investor Behavior: The Psychology of Financial Planning and Investing, Chapter 20, $365-$ 380. John Wiley \& Sons, Inc., Hoboken, NJ, USA.

Ku, G. (2008a). Before escalation: Behavioral and affective forecasting in escalation of commitment. Personality and Social Psychology Bulletin, 34(11), 1477-1491.

Ku, G. (2008b). Learning to de-escalate: The effects of regret in escalation of commitment. Organizational Behavior and Human Decision Processes, 105(2), 221-232.

Lehenkari, M. (2012). In search of the underlying mechanism of the disposition effect. Journal of Behavioral Decision Making, 25(2), 196-209

Lee, C.J., and Andrade, E.B. (2011). Fear, social projection, and financial decision making. Journal of Marketing Research, 48(SPL), S121-S129.

Lee, C.J., and Andrade, E.B. (2015). Fear, excitement, and financial risk-taking. Cognition and Emotion, 29(1), 178-187.

Lin, S., and Rassenti, S. (2012). Are under-and over-reaction the same matter? Experimental evidence. Journal of Economic Behavior and Organization, 84(1), 39-61.

Liu, Y.J., Tsai, C.L., Wang, M.C., and Zhu, N. (2010). Prior consequences and subsequent risk taking: New field evidence from the Taiwan Futures Exchange. Management Science, 56(4), 606-620.

Lo, A.W., and Repin, D.V. (2002). The psychophysiology of real-time financial risk processing. Journal of Cognitive Neuroscience, 14(3), 323-339.

Lucey, B.M., and Dowling, M. (2005). The Role of Feelings in Investor Decision-Making. Journal of economic surveys, $19(2), 211-237$.

Massa, M., and Simonov, A. (2005). Behavioral biases and investment. Review of Finance, 9(4), 483507.

Moore, D.A., and Healy, P.J. (2008). The trouble with overconfidence. Psychological review, 115(2), 502. 
Muradoglu, G., and Harvey, N. (2012). Behavioural finance: the role of psychological factors in financial decisions. Review of Behavioral Finance, 4(2), 68-80.

Nelson, M.W., Bloomfield, R., Hales, J.W., and Libby, R. (2001). The effect of information strength and weight on behavior in financial markets. Organizational Behavior and Human Decision Processes, 86(2), 168-196.

Nguyen, Y., and Noussair, C.N. (2014). Risk aversion and emotions. Pacific Economic Review, 19(3), 296-312.

Odean, T. (1998a). Are investors reluctant to realize their losses? Journal of Finance, 53(5), 17751798.

Odean, T. (1998b). Volume, volatility, price, and profit when all traders are above average. Journal of Finance, 53(6), 1887-1934.

Oehler, A., Heilmann, K., Läger, V., and Oberländer, M. (2003). Coexistence of disposition investors and momentum traders in stock markets: experimental evidence. Journal of International Financial Markets, Institutions and Money, 13(5), 503-524.

Pinegar, J.M. (2002). Losing sleep at the market: Comment. American Economic Review, 92(4), 1251-1256.

Rabin, M. (2002), Inference by believers in the law of small numbers. Quarterly Journal of Economics 117(3), 775-816.

Raghubir, P., and Das, S. R. (1999). A case for theory-driven experimental enquiry. Financial Analysts Journal, 55(6), 56-79.

Rau, H.A. (2014). The disposition effect and loss aversion: Do gender differences matter?. Economics Letters, 123(1), 33-36.

Rick, S. and Loewenstein, G. (2008) The role of emotion in economic behaviour. In Lewis, M., Haviland-Jones, J.M., and Feldman Barrett, L. (Eds.) Handbook of Emotions, Third Edition, The Guilford Press, New York. 
Rötheli, T.F. (2011). Pattern-based expectations: International experimental evidence and applications in financial economics. Review of Economics and Statistics, 93(4), 1319-1330.

Rouwenhorst, K.G. (1998). International momentum strategies. The Journal of Finance, 53(1), $267-$ 284.

Saunders Jr, E.M. (1993). Stock Prices and Wall Street Weather. American Economic Review, 83(5), 1337-45.

Shapira, Z., and Venezia, I. (2001). Patterns of behavior of professionally managed and independent investors. Journal of Banking and Finance, 25(8), 1573-1587.

Shefrin, H. (2000). Beyond greed and fear: Understanding behavioral finance and the psychology of investing. Harvard Business School Press, Boston.

Shefrin, H., and Statman, M. (1985). The disposition to sell winners too early and ride losers too long: Theory and evidence. Journal of Finance, 40(3), 777-790.

Shiller, R.J., (2005). Irrational Exuberance, 2nd Edition, Princeton University Press. Princeton, New Jersey.

Shiv, B., Loewenstein, G., Bechara, A., Damasio, H., and Damasio, A.R. (2005). Investment behavior and the negative side of emotion. Psychological Science, 16(6), 435-439.

Shumway, T. (2010). Mood. In Baker H.K. and Nofsinger, J.R. (Eds.) Behavioral Finance: Investors, Corporations, and Markets, Chapter 36, 671-679. John Wiley \& Sons, Inc., Hoboken, NJ, USA.

Statman, M., Thorley, S., and Vorkink, K. (2006). Investor overconfidence and trading volume. Review of Financial Studies, 19(4), 1531-1565.

Strahilevitz, M.A., Odean, T., and Barber, B.M. (2011). Once burned, twice shy: How naïve learning, counterfactuals, and regret affect the repurchase of stocks previously sold. Journal of Marketing Research, 48(SPL), S102-S120.

Summers, B., and Duxbury, D. (2012). Decision-dependent emotions and behavioral biases. Organizational Behavior and Human Decision Processes, 118(2), 226-238. 
Thaler, R.H., and Johnson, E.J. (1990). Gambling with the house money and trying to break even: The effects of prior outcomes on risky choice. Management science, 36(6), 643-660.

Tsai, M-H., and Young, M.J. (2010). Anger, fear, and escalation of commitment. Cognition and Emotion, 24(6), 962-973.

Weber, M., and Camerer, C.F. (1998). The disposition effect in securities trading: An experimental analysis. Journal of Economic Behavior and Organization, 33(2), 167-184.

Whyte, G. (1986). Escalating commitment to a course of action: A reinterpretation. Academy of Management Review, 11(2), 311-321.

Wong, K.F.E., and Kwong, J.Y.Y. (2007). The role of anticipated regret in escalation of commitment. Journal of Applied Psychology, 92(2), 545-554.

Zeelenberg, M., van Dijk, W.W., and A.S.R. Manstead. (1998). Reconsidering the relation between regret and responsibility. Organizational Behavior and Human Decision Processes, 74(3) 254-272. 